\title{
Antimicrobial Resistance of Enterococaus sp. Isolated from the Intestinal Tract of Patients from a University Hospital in Brazil
}

\author{
Andresa Maschieto, Roberto Martinez*, Izabel Cristina Vanzato Palazzo, \\ Ana Lúcia da Costa Darini ${ }^{+}$
}

\begin{abstract}
Departamento de Análises Clínicas, Toxicológicas e Bromatológicas, Faculdade de Ciências Farmacêuticas *Departamento de Clínica Médica, Faculdade de Medicina de Ribeirão Preto, USP, 14040-903 Ribeirão Preto, SP, Brasil
\end{abstract}

This study reports the results about antimicrobial resistance of Enterococcus spp. isolated from intestinal tract of patients from a university hospital in Brazil. The identification of strains at species level was performed by conventional biochemical tests, API 20 Strep (bioMérieux), and polymerase chain reaction assay. The specie distribution was E. faecium (34\%), followed by E. faecalis (33\%), E. gallinarum (23.7\%), E. casseliflavus (5.2\%), E. avium $(1 \%)$, and $\mathrm{E}$. hirae (1\%). Intrinsic resistance to vancomycin characterized by presence of vanC genes was found in $\mathrm{E}$. gallinarum and $\mathrm{E}$. casseliflavus. The high prevalence of VanC phenotype enterococci is very important because these species have been reported as causing a wide variety of infections. Vancomycin-resistant E. faecium or E. faecalis were not found and no one isolate of these species was a $\beta$-lactamase producer. Thirteen clinical isolates of enterococci $(13.4 \%)$ showed multiresistance patterns, which were defined by resistance to three classes of antibiotics plus resistance to at least one aminoglycoside (gentamicin and/or streptomycin). The resistance to several antimicrobials shown by enterococcal strains obtained in this study is of concern because of the decrease in the therapeutic options for treatment of infections caused by enterococci.

Key words: enterococci - resistance - antimicrobials - Brazil

Enterococci are widespread in nature and are part of the commensal flora of the human gastrointestinal and genitourinary tracts. Enterococci are often implicated in infections of the urinary tract and abdomen or superficial wounds of hospitalized patients, but can also cause bacteremia, endocarditis, perinatal infections, and, occasionally, meningitis or pneumonia. Thus, enterococci are increasing in importance as the cause of hospital-acquired infections. In addition, enterococci colonizing serve as reservoir for antibiotic resistance genes that can be transferred among enterococci and can be acquired by other bacteria (Dukta-Malen et al. 1994, Leclerq 1997).

Several studies have documented that enterococcal infections are most commonly caused by the patients own commensal flora. Colonization may occur long before or immediately before infection, but either way, it plays a major role in the development of nosocomial infection (Montecalvo et al. 1995).

Enterococal antimicrobial resistance to several antimicrobials, particularly resistance to high concentrations of penicillin and gentamicin or to glycopeptides, have hindered the treatment of serious infections caused by enterococci. The synergistic combinations among amynoglycosides and a cell-wall active antibiotic (i.e. amoxicillin or vancomycin) have been implicated in these resistant strains.

Financial support: Conselho Nacional de Desenvolvimento Científico e Tecnológico (464789/200-1), Pró-Reitoria de Pesquisa, Universidade de São Paulo

${ }^{+}$Corresponding author. Fax: +55-16-6331936.

E-mail: aldarini@fcfrp.usp.br

Received 8 June 2004

Accepted 15 September 2004
This paper reports a study conducted to determine antimicrobial resistance of Enterococcus spp. isolated from the intestinal tract of patients from a university hospital in Brazil.

\section{MATERIALSAND METHODS}

Bacterial strains and species identification - From May 2001 to June 2002, 37 stools and 101 rectal swabs were obtained from 125 hospitalized patients in hospital wards where vancomycin and or other antimicrobials are frequently used: Internal Medicine, Infectious Diseases, Kidney Transplant, Bone Marrow Transplant, Emergency Unit, Hematology, and Intensive Therapy Unit at the Hospital das Clínicas, Faculty of Medicine of Ribeirão Preto, University of São Paulo, a university hospital in Brazil, with 551 beds, that admits annually about 34,075 in patients and attends other 524,574 out patients. The patients included in this study were hospitalized at least for five days. All samples were collected randomly and there was no report of any gastrointestinal infection in the patients involved in this study.

The study protocol was approved by the Hospital's Ethical Committee (Process 6539/00).

The samples were plated onto Bile Esculin Azide Agar (Becton, Dickinson \& Co.), a selective medium with bileesculin and sodium azide. Five to six isolated colonies were identified from each plate and only those that presented some difference in minimum inhibitory concentration (MIC) and/or specie identification were considered for each patient.

Isolates recovered from stool or rectal swabs were presumptively identified as enterococci by colonial morphology, Gram's stain, the absence of catalase production, the presence of pyrrolidonylarylamidase by hidrolisis of Lpyrrolidonil- $\beta$-naphthylamide (Becton, Dickinson \& Co.), 
tolerance to $6.5 \%$ sodium chloride and ability to grow at $10^{\circ} \mathrm{C}$ and $45^{\circ} \mathrm{C}$. Species identification was carried out with a test scheme proposed by Facklam et al. (1999) that is based on carbohydrate fermentation and arginine deamination. Carbohydrate fermentation tests were perfomed in agar containing $1 \%$ of the sugar being tested. Arginine deamination was tested with Moeller arginine decarboxylase broth. Yellow pigmentation was observed after over night growth on Müeller Hinton agar (Merck) supplemented with 5\% sheep blood and by taking a sweep of the plate with a cotton swab. The pyruvate utilization test was observed with a broth containing $1 \%$ pyruvate (Ruoff et al. 1999, MacFaddin 2000). The identification of some species was performed by API 20 Strep (bioMérieux).

Amplification by polymerase chain reaction (PCR) for species identification - PCR was performed to confirm some species identification and to detect vancomycin resistance mediated by van genes. Two colonies were obtained from a fresh subculture and were resuspended in $100 \mu 1$ sterile water (Sigma, St. Louis, US). Two microliters of the suspension were added to each PCR mixture consisting of $23 \mu \mathrm{l}$ with the following components: $0.625 \mathrm{U}$ Taq polymerase (Life Technologies, UK), $0.2 \mathrm{mM}$ each deoxynucleoside triphophate (dNTP), $2.0 \mathrm{mM} \mathrm{MgCl}_{2}, 1 \mathrm{x}$ PCR buffer ( $20 \mathrm{mMTris}, 50 \mathrm{mM} \mathrm{KCl}), 25 \mathrm{pmol}$ of each primer according to Dukta-Malen et al. (1995) (Table I). After an initial denaturation step at $94^{\circ} \mathrm{C}$ for 2 min, the mixture was subjected to 30 cycles under the following conditions: $30 \mathrm{~s}$ at $94^{\circ} \mathrm{C}, 30 \mathrm{~s}$ at $54^{\circ} \mathrm{C}$, and $30 \mathrm{~s}$ at $72^{\circ} \mathrm{C}$, followed by a final extension step at $72^{\circ} \mathrm{C}$ for $10 \mathrm{~min}$. Amplified products were analyzed by $1.5 \%$ agarose gel electrophoresis and the size of the amplification products was estimated by comparison with the molecular size standard 123 pb ladder.

Control strains: E. faecalis NCTC 775, E. faecium NCTC 7171, E. gallinarum NCTC 12359 , and E. casseliflavus NCTC 12361.

Determination of minimum inhibitory concentration - The MIC of the following antimicrobial agents was performed by the agar dilution method according to NCCLS guidelines (2000) with antibiotic dilutions ranging from 0.125 to $256 \mu \mathrm{g} / \mathrm{ml}$ : vancomycin, penicillin, chloramphenicol, tetracycline, erythromycin, and quinupristindalfopristin. Bacterial suspensions equal to a $0.5 \mathrm{McF}$ arland standard were prepared and inoculated onto antibiotic containing medium with Steers replicator to yield a final inoculum of $10^{8} \mathrm{cfu} / \mathrm{spot}$. Plates were incubated in ambient air at $35^{\circ} \mathrm{C}$ for $24 \mathrm{~h}$. The MIC was defined as the lowest antibiotic concentration which gave a complete absence of growth (NCCLS 2000).

Detection of high level aminoglycoside resistance (HLAR) - The screening of high level aminoglycoside resistance was performed in agar dilution plates prepared with brain heart infusion (BHI - Oxoid, Basingstoke, England) agar with $500 \mathrm{mg}$ gentamicin per ml and $2000 \mu \mathrm{g}$ streptomycin per $\mathrm{ml}$. The plates were inoculated by spotting $10 \mu \mathrm{l}$ of a suspension prepared from growth on an 18$24 \mathrm{~h}$ agar plate and adjusted to a $0.5 \mathrm{Mc}$ Farland standard, giving a final inoculum of $10^{8} \mathrm{cfu} / \mathrm{spot}$. Plates were incubated at $35^{\circ} \mathrm{C}$ for $24 \mathrm{~h} / 48 \mathrm{~h}$ (NCCLS 2000).

Detection of $\beta$-lactamase production - All enterococci isolates were tested for $\beta$-lactamase production with nitrocefin (Oxoid) according to the manufacture's instructions. Nitrocefin solution was dropped onto a single colony of an overnight culture. Development of a red color would indicate a positive result.

Control strains: S. aureus ATCC 29213 was used as a positive control and $S$. aureus ATCC 25923 as negative control for $\beta$-lactamase detection.

\section{RESULTS}

Enterococcus spp. were isolated in 67 (53.6\%) of the 125 patients included in this study, and 15 of them presented more than one specie of enterococci in the faecal samples.

A total of 97 enterococcal isolates were obtained from 67 patients. The enterococcal isolates were identified to species level and the distribution were E. faecium (34\%) followed by E. faecalis (33\%), E. gallinarum (23.7\%), E. casseliflavus (5.2\%), E. durans (2\%), E. avium (1\%), and E. hirae (1\%). The scheme proposed by Facklam et al. (1999) did not permit the specie identification in some cases, thus we do need perform the species identification by PCR or API test. No one patient showed only E. avium in faecal samples, but this species was isolated in one patient in association with E. gallinarum, E. casseliflavus, and $E$. faecalis. The association of species most frequently found was E. faecium-E. faecalis $(7.5 \%)$ and E. faeciumE. gallinarum $(7.5 \%)$. Six patients harbored other association of enterococci species in gastrointestinal tract as indicated in Table II.

The vancomycin resistance genotype in E. gallinarum

TABLE I

Sequences of the species-specific primers used in this study

\begin{tabular}{lccl}
\hline Species & Gene & Product $(\mathrm{bp})$ & Primers $\left(5^{\prime}-3^{\prime}\right)$ \\
\hline Enterococcus faecalis & $d d l_{\text {E. faecalis }}$ & 941 & $\begin{array}{l}\text { ATCAAGTACAGTTAGTCTT } \\
\text { ACGATTCAAAGCTAACCTG }\end{array}$ \\
Enterococcus faecium & $d d l_{\text {E. faecium }}$ & 550 & $\begin{array}{l}\text { GCAAGGCTTCTTAGAGA } \\
\text { CATCGTGTAAGCTAACTTC }\end{array}$ \\
Enterococcus gallinarum & vanC-1 & 822 & $\begin{array}{l}\text { GGTATCAAGGAAACCTC } \\
\text { CTCCGCCATCATAGCT }\end{array}$ \\
Enterococcus casseliflavus & vanC $2-3$ & 439 & CTCCTACGATTCTCTTG \\
CGAGCAAGACCTTTAAG
\end{tabular}

bp: base pairs. All primers used in this study were described by Dukta-Malen et al. (1995) 
TABLE II

Distribution of enterococci species in the gastrointestinal tract of the patients studied

\begin{tabular}{lc}
\hline Enterococcus species & $\begin{array}{c}\text { Patients with enterococci in } \\
\text { gastrointestinal tract } \\
\text { Nr of patients }(\%)\end{array}$ \\
\hline E. faecalis & $19(28.3)$ \\
E. faecium & $16(23.9)$ \\
E. gallinarum & $13(19.4)$ \\
E. casseliflavus & $1(1.5)$ \\
E. durans & $1(1.5)$ \\
E. hirae & $1(1.5)$ \\
E. faecalis/ E. faecium & $5(7.5)$ \\
E. faecium/ E. gallinarum & $5(7.5)$ \\
Enterococcus spp. & $6(8.9)$ \\
\hline Total & $67(100)$ \\
\hline
\end{tabular}

$a$ : patients colonized by other enterococci association (two or more species).

and E. casseliflavus were determined by PCR and all gave positive results for the presence of vanC-1 and vanC-2 genes, respectively.

The distribution of antibacterial resistance according to species is presented in Table III. The results show that only E. gallinarum and E. casseliflavus were resistant to vancomycin. Resistance to penicillin among the E. faecium and the E. faecalis isolates were $9.1 \%$ and $9.4 \%$, respectively. In contrast, resistance to chloramphenicol was $33.3 \%$ and $40.6 \%$, erythromycin $66.7 \%$ and $75 \%$, tetracycline $42.4 \%$ and $56.2 \%$, and to quinupristin-dalfopristin $3 \%$ and $12.5 \%$, respectively. E. faecium and E. faecalis, with high-level gentamicin resistance, were $18.2 \%$ and $28.1 \%$, respectively. High-level streptomycin resistance was detected in $21.2 \%$ of E. faecium and $21.9 \%$ of $E$. faecalis isolates. E. avium and E hirae were susceptible to all drugs tested (Table III).

Although the antibiotic resistance mentioned can exist independently, it can be combined in a single strain that could be a multiresistant strain. In this study the multiresistant strain, defined as that presenting resistance for at least one aminoglycoside (gentamicin and/or streptomycin) plus resistance for another three classes of antibiotics, was verified in 13 isolates of Enterococcus spp. (Table IV).

Neither isolate of E. faecalis nor E. faecium was a $\beta$ lactamase producer.

\section{DISCUSSION}

This study investigated the species occurrence and antibacterial resistance patterns of enterococci isolated from rectal swabs of hospitalized patients in clinics that have high-risk for vancomycin-resistant enterococci (VRE) colonization in a university hospital in Brazil. The transmission dynamics of VRE and factors contributing to their dissemination are complex. Numerous variables and interactions need to be considered, however gastrointestinal VRE colonization appears to play a major role in the development of VRE infections (Montecalvo et al. 1995).

The isolates obtained in this study were E. faecium (34\%) followed by E. faecalis $(33 \%)$ and we do not have a clear dominance of E. faecalis as expected. According to date published in other Brazilian study (Mondino et al. 2003), E. faecalis was the prevalent specie (53.6\%) among intestinal strains. A diversity in the species distribution might be obtained when enterococci isolated in different geographical regions are involved. The most frequent enterococcal species isolated from clinical specimens are E. faecalis and E. faecium, which are responsible for $90 \%$ of nosocomial infections (Mutnick et al. 2003), however according to Kühn et al. (2003), these two species represented $78 \%$ of the enterococci isolated from intestinal tract of hospitalized patients.

Motile enterococci, including E. gallinarum and $E$. casseliflavus, are rarely encountered in human clinical specimens and are primarily found in the gastrointestinal tract in poultry, in foods, and in domestic fowls. Although these species are infrequently isolated from clinical specimens, they have been implicated in a wide variety of invasive infections in humans, especially immunocompromised

TABLE III

Species distribution of enterococci resistant to antimicrobials

\begin{tabular}{|c|c|c|c|c|c|c|c|c|}
\hline \multirow{2}{*}{$\begin{array}{l}\text { Enterococcus species } \\
\text { (number tested) }\end{array}$} & \multicolumn{8}{|c|}{ Antimicrobials - Number of strains (\%) } \\
\hline & VAN & PEN & CLO & ERI & TET & QUI/DAL & $\mathrm{GEN}^{a}$ & $\mathrm{STR}^{a}$ \\
\hline E. faecalis (32) & - & $3(9.4)$ & $13(40.6)$ & $24(75)$ & $18(56.2)$ & $4(12.5)$ & $9(28.1)$ & $7(21.9)$ \\
\hline E. faecium (33) & - & $3(9.1)$ & $11(33.3)$ & $22(66.7)$ & $14(42.4)$ & $1(3)$ & $6(18.2)$ & $7(21.2)$ \\
\hline E. gallinarum (23) & $23(100)$ & $1(4.3)$ & $3(13)$ & $8(34.8)$ & $7(30.4)$ & $2(8.7)$ & $3(13)$ & $1(4.3)$ \\
\hline E. casseliflavus (5) & $5(100)$ & - & - & $2(40)$ & $1(20)$ & - & - & - \\
\hline E. durans (2) & - & - & $2(100)$ & $1(50)$ & - & - & - & - \\
\hline E. avium (1) & - & - & - & - & - & - & - & - \\
\hline E. hirae (1) & - & - & - & - & - & - & - & - \\
\hline Total (97) & $28(28.9)$ & $7(7.2)$ & 29 (29.9) & $57(58.7)$ & $40(41.2)$ & $7(7.2)$ & $18(8.5)$ & 15 (15.5) \\
\hline
\end{tabular}

VAN: vancomycin; PEN: penicillin; CLO: chloramphenicol; ERI: erythromycin, TET: tetracycline, QUI/DAL: quinupristin-dalfopristin; GEN: gentamicin; STR: streptomycin. Isolates with MIC $\geq 32 \mathrm{mg} / \mathrm{ml}$ for vancomycin and chloramphenicol, $\geq 16 \mathrm{mg} / \mathrm{ml} \mathrm{for} \mathrm{penicillin}$ and tetracycline, $\geq 8 \mathrm{mg} / \mathrm{ml}$ for erythromycin, $\geq 4 \mathrm{mg} / \mathrm{ml}$ for quinupristin/dalfopristin, $>500 \mathrm{mg} / \mathrm{ml}$ for gentamicin, $>2000 \mathrm{mg} / \mathrm{ml} \mathrm{for}$ streptomycin were considered to be resistant for these agents (NCCLS 2000); $a$ : strains were screened for high level aminoglycoside resistance. 
TABLE IV

Multiresistance patterns of enterococci strains

\begin{tabular}{|c|c|c|c|c|c|c|c|c|}
\hline \multirow{2}{*}{$\begin{array}{l}\text { Enterococcus } \\
\text { strains }\end{array}$} & \multicolumn{6}{|c|}{ MIC $(\mu \mathrm{g} / \mathrm{ml})$} & \multicolumn{2}{|c|}{ HLAR } \\
\hline & VAN & PEN & CLO & ERI & TET & $\overline{\text { QUI/DAL }}$ & GEN & SM \\
\hline E. faecalis HC $131 \mathrm{~S} / \mathrm{A}$ & $2(\mathrm{~S})$ & $16(\mathrm{R})$ & $128(\mathrm{R})$ & $>256(\mathrm{R})$ & 64(R) & $0,5(\mathrm{~S})$ & $>500(\mathrm{R})$ & $<2000(\mathrm{~S})$ \\
\hline E. faecium $\mathrm{HC} 135 \mathrm{~S} / \mathrm{A}$ & $4(\mathrm{~S})$ & $4(S)$ & $64(\mathrm{R})$ & $>256(\mathrm{R})$ & 256(R) & $1(\mathrm{~S})$ & $>500(\mathrm{R})$ & $<2000(\mathrm{~S})$ \\
\hline E. faecalis $\mathrm{HC} 135 \mathrm{~S} / \mathrm{B}$ & $4(\mathrm{~S})$ & $1(\mathrm{~S})$ & $64(\mathrm{R})$ & $>256(\mathrm{R})$ & 256(R) & $1(\mathrm{~S})$ & $>500(\mathrm{R})$ & $<2000(\mathrm{~S})$ \\
\hline E. faecium $\mathrm{HC} 137 \mathrm{~S} / \mathrm{A}$ & $2(\mathrm{~S})$ & $1(\mathrm{~S})$ & $64(\mathrm{R})$ & $>256(\mathrm{R})$ & $128(\mathrm{R})$ & $0,5(\mathrm{~S})$ & $>500(\mathrm{R})$ & $<2000(\mathrm{~S})$ \\
\hline E. faecalis HC 141 S/A & $1(\mathrm{~S})$ & $4(\mathrm{~S})$ & $64(\mathrm{R})$ & $256(\mathrm{R})$ & $16(\mathrm{R})$ & $0,5(\mathrm{~S})$ & $>500(\mathrm{R})$ & $<2000(\mathrm{~S})$ \\
\hline E. faecalis $\mathrm{HC} 153 \mathrm{~S} / \mathrm{A}$ & $4(S)$ & $1(\mathrm{~S})$ & $32(\mathrm{R})$ & $128(\mathrm{R})$ & $32(\mathrm{R})$ & $1(S)$ & $<500(\mathrm{~S})$ & $>2000(\mathrm{R})$ \\
\hline E. faecalis $\mathrm{HC} 154 \mathrm{~S} / \mathrm{C}$ & $4(S)$ & $0,5(\mathrm{~S})$ & $32(\mathrm{R})$ & $128(\mathrm{R})$ & $32(\mathrm{R})$ & $1(\mathrm{~S})$ & $<500(\mathrm{~S})$ & $>2000(\mathrm{R})$ \\
\hline E. faecium HC 156 S/A & $2(\mathrm{~S})$ & $16(\mathrm{R})$ & $32(\mathrm{R})$ & $>256(\mathrm{R})$ & $128(\mathrm{R})$ & $1(\mathrm{~S})$ & $<500(\mathrm{~S})$ & $>2000(\mathrm{R})$ \\
\hline E. gallinarum $\mathrm{HC} 185$ S/A & $8(\mathrm{~S})$ & $2(\mathrm{~S})$ & $32(\mathrm{R})$ & $>256(\mathrm{R})$ & $128(\mathrm{R})$ & $2(\mathrm{~S})$ & $>500(\mathrm{~S})$ & $>2000(\mathrm{R})$ \\
\hline E. faecalis $\mathrm{HC} 186 \mathrm{~S} / \mathrm{B}$ & $1(\mathrm{~S})$ & $16(\mathrm{R})$ & $64(\mathrm{R})$ & $8(\mathrm{R})$ & $0,5(S)$ & $1(\mathrm{~S})$ & $<500(\mathrm{~S})$ & $>2000(\mathrm{R})$ \\
\hline E. faecalis HC $221 \mathrm{~S} / \mathrm{A}$ & $2(\mathrm{~S})$ & $8(\mathrm{~S})$ & 64(R) & $>256(\mathrm{R})$ & $0,125(\mathrm{~S})$ & $4(\mathrm{R})$ & $>500(\mathrm{R})$ & $<2000(\mathrm{~S})$ \\
\hline E. faecalis $\mathrm{BAC} 58 \mathrm{~S} / \mathrm{A}$ & $2(\mathrm{~S})$ & $2(\mathrm{~S})$ & $32(\mathrm{R})$ & $>256(\mathrm{R})$ & $32(\mathrm{R})$ & $0,5(\mathrm{~S})$ & $>500(\mathrm{R})$ & $>2000(\mathrm{R})$ \\
\hline E. faecalis $\mathrm{BAC} 61 \mathrm{~S} / \mathrm{C}$ & $4(S)$ & $4(S)$ & 64(R) & $>256(\mathrm{R})$ & $32(\mathrm{R})$ & $4(\mathrm{R})$ & $<500(\mathrm{~S})$ & $>2000(\mathrm{R})$ \\
\hline
\end{tabular}

MIC: minimum inhibitory concentration determined by agar dilution method with breakpoints proposed by NCCLS (2000); VAN: vancomycin; CLO: chloramphenicol; ERI: erythromycin; TET: tetracycline; QUI/DAL: quinupristin/dalfopristin; GEN: gentamycin; SM: streptomycin; S: susceptible; R: resistant; HLAR: high level aminoglycoside resistance

or chronically ill patients, and sometimes are nosocomially acquired (Reid et al. 2001, Dargere et al. 2002).

In this study the prevalence of vanC phenotype enterococci was significantly higher $(23.7 \%$ of E. gallinarum and $5.2 \%$ of E. casseliflavus) than in several studies that reported intestinal colonization by enterococci van $C$. In 1997 , the prevalence of colonization by these species in another hospital in Brazil was 1.2\% (Cereda et al. 1997), Canada presented $5 \%$ of these species (Toye et al. 1997), Lebanon 1.4\% (Zouain \& Araj 2001), and Kuwait 4.5\% (Udo et al. 2003). The high prevalence obtained in this study is very important because several studies have reported infection or colonization by E. gallinarum carrying genes that determine high resistance to vancomycin: E. gallinarum van $A$ in Belgium (Dukta-Malen et al. 1994), in Italy (Biavasco et al. 2001), in Japan (Takayama et al. 2003), and in Brazil (Camargo et al. 2004). E. gallinarum $\operatorname{van} B$ in Switzerland (Liassine et al. 1998) and Australia (Schooneveldt et al. 2000).

Several hospitals located in São Paulo and some other Brazilian cities reported both outbreaks and isolated cases of VRE infection/colonization (Zanella et al. 1999, 2003, Cereda et al. 2001, 2002, Reis et al. 2001), however the enterococci strains obtained in this study were van susceptible, indicating that vancomycin retains its therapeutic efficacy against $E$. faecalis and E. faecium in this hospital.

The prevalence of resistance to penicillin remains low in this hospital, indicating that this antimicrobial agent would be a therapeutic option. On other hand, the absence of vancomycin resistance among enterococci strains studied permits the use of vancomycin in combination with aminoglycoside as an alternative to penicillin to treat allergic patients or against $\beta$-lactamase producing strains. However, the high rate of aminoglycoside resistance obtained in this study could not maintain a therapeutic efficacy and the synergistic effect when combined with cell wall active agents such as vancomycin and ampicillin in the treatment of enterococcal infections.

The high rates of resistance to chloramphenicol, erythromycin and tetracycline observed in this study restricts the use of these drugs at this hospital.

Quinupristin-dalfopristin is almost inactive against $E$. faecalis. In contrast, most isolates of E. faecium are susceptible to this agent. The mechanism of resistance to dalfopristin in E. faecalis is related with an efflux pump that appears to be intrinsic in this species (Eliopoulos 2003). Date obtained in this study are in concordance with those published because $13 \%$ of the E. faecalis were found to be resistant to quinupristin-dalfopristin. However, among E. faecium isolates obtained in this study, 3.8\% showed resistance to this agent.

Although the antibiotic resistance mentioned above can exist independently, it can be combined in a single strain resulting in multiresistance. The several multiresistant enterococci strains obtained in this study are a cause of concern due to limitations in clinical use, specially by loss of synergistic combinations which are often needed for treatment of enterococcal infections (Schouten 1999).

In spite of the conditions that could facilitate VRE colonization, we did not find either vancomycin resistant E. faecalis or E. faecium in this hospital. However, recommendation to prevent the spread of VRE are essential due the resistance to several antimicrobials showed by enterococcal strains obtained in this study.

\section{REFERENCES}

Biavasco F, Paladini C, Vignaroli C, Foglia G, Manso E, Varaldo PE 2001. Recovery from a single blood culture of two Enterococcus gallinarum isolates carrying both vanC-1 and vanA cluster genes and differing in glycopeptide susceptibility. Eur J Clin Microbiol Infect Dis 5: 309-314.

Camargo ILBC, Barth AL, Pilger K, Seligman BGS, Machado A, Darini ALC 2004. Enterococcus gallinarum carrying vanA gene cluster. First report in Brazil. Braz J Med Biol 
Res, in press.

Cereda RF, Gales AC, Silbert S, Jones RN, Sader HS 2002. Molecular typing and antimicrobial susceptibility of vancomycin-resistant Enterococcus faecium in Brazil. Infect Control Hosp Epidemiol 23: 19-22.

Cereda RF, Pignatari AC, Hashimoto A, Sader H 1997. In vitro antimicrobial activity against enterococci isolated in a university hospital in São Paulo, Brazil. Braz J Infect Dis 1: 83-90.

Cereda RF, Sader HS, Jones RN, Sejas L, Machado AM, Zanatta YP, Rego STMS, Medeiros EAS 2001. Enterococcus faecalis resistant to vancomycin and teicoplanin (VanA phenotype) isolated from a bone marrow transplanted patient in Brazil. Braz J Infect Dis 5: 40-46.

Dargere S, Vergnaud M, Verdon R, Saloux E, LePagE O, Leclercq R, Bazin C 2002. Enterococcus gallinarum endocarditis occurring on native heart valves. J Clin Microbiol 40: 23082310.

Dutka-Malen S, Blaimont B, Wauters G, Courvalin P 1994. Emergence of high-level resistant Enterococcus gallinarum and Enterococcus casseliflavus. Antimicrob Agents Chemother 34: 1675-1677.

Dukta-Malen S, Evers S, Courvalin P 1995. Detection of glycopeptide resistance genotypes and identification to the species level of clinically relevant enterococci by PCR. J Clin Microbiol 33: 24-27.

Eliopoulos GM 2003. Quinupristin-Dalfopristin and Linezolid: evidence and opinion. Clin Infect Dis 36: 473-481.

Facklam RR, Sahm DF, Teixeira ALM 1999. Enterococcus. In PR Murray, EJ Baron, MA Pfaller, FC Tenover, RH Yolken (eds), Manual of Clinical Microbiology, 7th ed., American Society for Microbiology, Washington DC, p. 297-315.

Kühn I, Iversen A, Burman LG, Olsson-Liljequist B, Franklin A, Finn M, Aarestrup F, Seyfarth AM, Franklin A, Finn M, Blanch AR, Vilanova X, Taylor H, Caplin J, Moreno MA, Dominguez L, Herrero IA, Möllby R 2003. Comparison of enterococcal populations in animals, humans, and the environment - A European study. Inter J Food Microbiol 88: 133-145.

Leclercq R 1997. Enterococci acquire new kinds of resistance. Clin Infect Dis 24 (Suppl. 1): 80S-84S.

Liassine N, Frei R, Jan I, Auckenthaler R 1998. Characterization of glycopeptide-resistant enterococci from a Swiss Hospital. J Clin Microbiol 36: 1853-1858.

MacFaddin JF 2000. Biochemical Tests for Identification of Medical Bacteria, 3rd ed., Lippincot Williams \& Wilkins, US, 912 pp.

Mondino SS, Castro AC, Mondino PJ, Carvalho MG, Silva KM, Teixeira LM 2003. Phenotypic and genotypic characterization of clinical and intestinal enterococci isolated from inpatients and outpatients in two Brazilian hospitals. Microb Drug Resist 9: 167-174.
Montecalvo MA, Lancestre H, Carraber M, Gedris C, Chung M, VanHorn K, Wormser GP 1995. Natural history of colonization with vancomycin resistant Enterococcus faecium. Infect Control Hosp Epidemiol 16: 680-685.

Mutnick AH, Biendenbach DJ, Jones RN 2003. Geographic variations and trends in antimicrobial resistance among Enterococcus faecalis and Enterococcus faecium in the SENTRY antimicrobial surveillance program (1997-2000). Diagn Microbiol Infect Dis 46: 63-68.

NCCLS-National Committee for Clinical Laboratory Standards 2000. Methods for Dilution Antimicrobial Susceptibility Tests for Bacteria that Grow Aerobically, 5th ed., Wayne, PA.

Reid KC, Cockerill FR, Patel R 2001. Clinical and epidemiological features of Enterococcus casseliflavus/flavescens and Enterococcus gallinarum bacteriemia: a report of 20 cases. Clin Infect Dis 32: 1540-1546.

Reis AO, Cordeiro JC, Machado AM, Sader HS 2001. In vitro antimicrobial activity of Linezolid tested against vancomycin-resistant enterococci isolated in Brazilian hospitals. Braz J Infect Dis 5: 243-251.

Ruoff KL, Whiley RA, Beighton D 1999. Streptococcus. In PR Murray, EJ Baron, MA Pfaller, FC Tenover, RH Yolken (eds), Manual of Clinical Microbiology, 7th ed., American Society for Microbiology, Washington DC, p. 283-296.

Schooneveldt JM, Marriott RK, Nimmo GR 2000. Detection of vanB determinant in Enterococcus gallinarum in Australia. J Clin Microbiol 38: 3902.

Schouten MA 1999. Vancomycin resistant enterococci. Prevalence in Europe. Clin Microbiol Infec 8 (Supp.1): 136.

Takayama Y, Sunakawa K, Akahoshi T 2003. Meningitis caused by Enterococcus gallinarum in patients with ventriculoperitoneal shunts. J Infect Chemother 9: 348-350.

Toye B, Shymanski J, Bobrowska M, Woods W, Ramotar K 1997. Clinical and epidemiologic significance of enterococci intrinsically resistant to vancomycin (possessing the VanC genotype). J Clin Microbiol 3: 3166-3170.

Udo EE, Al-Sweih N, Phillips AO, Chugh TD 2003. Species prevalence and antibacterial resistance of enterococci isolated in Kuwait hospitals. J Med Microbiol 52: 163-168.

Zanella RC, Brandileone MCC, Bokermann S, Almeida SCG, Valdetaro F, Votório F, Moreira MFA, Villins M, Salomão R, Pignatari AC 2003. Phenotypic and genotypic characterization of VanA Enterococcus isolated during the first nosocomial outbreak in Brazil. Microb Drug Resist 9: 283-291.

Zanella RC, Valdetaro F, Lovgren M, Tyrrel GJ, Bokermann S, Almeida SCG, Vieira VSD, Brandileone MCC 1999. First confirmed case of a vancomycin-resistant Enterococcus faecium with Van A phenotype from Brazil: isolation from a meningitis case in São Paulo. Microb Drug Resist 5: 159162.

Zouain MG, Araj GF 2001. Antimicrobial resistance of enterococci in Lebanon. Int J Antimicrob Agents 17: 209-213. 
